\begin{tabular}{|l|l|l}
\hline & $\begin{array}{l}\text { Proceedings of the } \\
\text { Informing Science }+\end{array}$ & $\begin{array}{l}\text { An Official Publication } \\
\text { of the Informing Science Institute } \\
\text { InformingScience.org }\end{array}$ \\
\hline
\end{tabular}

June 23 - 28 2018, La Verne, California, USA

\title{
INTERACTIVE 3D REPRESENTATION OF BUSINESS CASE STUDIES IN THE ClassRoOM
}

\author{
Andrew Zaliwski* \\ Whitireia Polytechnic, Auckland, \\ Andrew.Zaliwski@,Whitireia.ac.nz \\ New Zealand \\ Karishma Kelsey \\ Whitireia Polytechnic, Auckland, \\ Karishma.Kelsey@,Whitireia.ac.nz \\ * Corresponding author \\ New Zealand
}

\begin{abstract}
Aim/Purpose

In our previous paper, we have proposed a methodology to deliver an applied business course to the multicultural audience having in mind embedding into the course cultural sensitivity and create a safe place for multicultural students to use own cultural metaphors in a learning place. We have proposed a fusion of ancient storytelling tradition creating an overall context for the teaching process and specific use of rich picture coming from Soft System Methodology (SSM). The used teaching approach is promising and brings the required results. However, the proposed method, to be fully effective requires a computerized supporting tool in a form of sophisticated graphical editor/presentation application displaying in real-time case study progress along with the in-class discussion. This tool is a central topic for this paper.

Background The existing tools like for example MS PowerPoint, MS Visio, or Prezi used by us so far cannot be used for our purpose as the interactive image update distract the students. The MS PowerPoint and Prezi require visible mode switching between design mode (edit) and presentation mode. Whereas MS Visio editing is too slow for our purposes. This switching or editing time create a meaningful distraction during the discussion.

Methodology As a solution for the above problem, the authors work on the development of own specialized tool using open source software Blender 3D

(http://blender.org) along with Python. The code will be released to open source domain to enable further co-operation with other researchers.

Contribution The described effort, if successful, should create a new presentation tool allowing among the other features, seamless in-class knowledge transfer and in the future will enable the way for gamification of case studies.
\end{abstract}

Accepted by Executive Review by Editor Eli Cohen on May 8, 2018.

Cite as: Zaliwski, A., \& Kelsey, K. (2018). Interactive 3D representation of business case studies in the classroom. Proceedings of the Informing Science and Information Technology Education Conference, La Verne, California, 65-78. Santa Rosa, CA: Informing Science Institute. https://doi.org/10.28945/4047

(CC BY-NC 4.0) This article is licensed to you under a Creative Commons Attribution-NonCommercial 4.0 International License. When you copy and redistribute this paper in full or in part, you need to provide proper attribution to it to ensure that others can later locate this work (and to ensure that others do not accuse you of plagiarism). You may (and we encourage you to) adapt, remix, transform, and build upon the material for any non-commercial purposes. This license does not permit you to use this material for commercial purposes. 
Interactive 3D Representation of Business Case Studies

Impact on Society A definite improvement of teaching quality in applied business (however, not limited to) with further possibility to extend to deliver courses e.g. for company's executives. The tool and methodology allow embedding cultural sensitivity into the learning process and will have an impact on digital inclusiveness.

Future Research The tool enables possibility for further analysis of the business situation by artificial intelligence interface. In fact, a whole interactive process of reaching the case conclusion may be observed (allowing collecting analytics and insights on teacher and student's behavior and performance).

Keywords digital inclusion, case teaching, visual knowledge transfer, visualization of business thinking

\section{BACKGROUND}

Business Case Studies are more (Ambrosini, Bowman, \& Collier, 2010; Arasti, Falavarjani, \& Imanipour, 2012; Duarte, 2013; Harner \& Rhee, 2014; Herreid, 2006;) or less (Herreid, 2004; Shugan, 2006) recognized as a research method or method of transfer of business experience to students by replacing the need for being long years immersed in the real company by the studying of pre-written stories describing real problem situations faced in the past by various companies. Many MBA courses massively utilize the case studies as the best-known tool for fast business experience transfer.

Since the year 2010, authors of this paper are continuing research on a new way of delivery cultural sensitive teaching stream to multicultural students as we have found that not satisfactory results of case studies teaching are caused by different understanding based on different cultural traditions that our students brought from their own home country. The purpose of our research is to give all students coming to New Zealand the same career chances independently of their cultural differences. Of course, the ideas presented are not limited only to New Zealand.

The core of the proposed method was described in detail in the paper (Kelsey \& Zaliwski, 2017b). Briefly, the method is based on creating a safe learning space where students may feel comfortable using their own cultural tradition, culturally related metaphors, analogies, short stories, and terms as building blocks in the process of co-operative learning. It was done primarily by specifically adopting talanoa methodology (Vaioleti, 2016) to applied business teaching. Talanoa is common (Kosara \& Mackinlay, 2013; Leavy, Wyeld, Hills, Barker, \& Gard, 2007; Meyers, 2003) for the all-Pacific Islands (also including Hawaii); eventually, it may be known under different names. There are also some common points with African Ubuntu approach.

Generally, the method makes use of ancient storytelling tradition intertwined with our version of well-known in information technology, so-called 'rich picture' (which is used as a core of Soft System Methodology (SSM)). The SSM was created to avoid technological bias when analyzing sociotechnical systems. SSM is a multipurpose methodology being already used in a variety of ways (Checkland, 2000; Ledington \& Donaldson, 1997; Munro \& Mingers, 2002; Wigal, 2009; Winter, 2006). The version of SSM used for purposes of our research is most closely associated with the last work of Peter Checkland, as presented in Checkland and Poulter (2010), Checkland and Winter (2006), and Checkland and Scholes, (1990).

The ideas and rules on which business is now functioning are primarily sourced from western countries, eventually middle-east with some local spice added (we are thinking here about large and medium corporations, not family-owned businesses which are still more traditional and not MBA soaked). Large companies are strong enough to interact with other businesses operations in other global areas and cultures and to enforce their rules. In our method, we are going to put that upside-down, and we will embed into business the tradition and approach items and traditions specific for many various cultures making teaching sensitive for these cultures on a learning stage. We believe that, as a result, 
our students will also be more sensitive to the other cultures. The above considerations, applied together to the modern business case studies, create a whole new way of teaching.

The current solution is based on the use of non-formal interactive 3D diagrams (inherited from the mentioned earlier "rich picture") reflecting on an on-going basis, the business case study teamwork moderated by a teacher. These diagrams are core visuals to represent the current progress toward the case problem solution.

The proposed method was used on several applied business courses having an impact on better student's grades. There was observed visible improvement in students' grades and observed changes in students' behavior toward more active in-class participation. The paper summarized research findings based on a large survey and proved the effectiveness of the proposed method. However, the whole process so far isn't possible to be fully realized according to our plans as the method is lacking proper support from dedicated computerized tools. The implementation and use of the method in classroom conditions are limited by the enormously large time required for proper preparation of the class meeting, so current research efforts (also partially addressed in this paper) are focused on reducing the teacher's preparation time. The currently existing tools like MS PowerPoint, MS Visio, and Prezi (http://www.prezi.com) (however, all of them are usable for making other types of presentations) do not enable the required level of interactivity among student's teams and teacher. For example, any ad-hoc update on current case pictorial representation requires switching between presentation mode and editing mode what breaks the current stream of discussion.

The next section of the paper summarizes the research problem.

\section{RESEARCH PROBLEM}

The goal of the project described in the paper is to find an interactive way (including appropriate visualization metaphors and interfaces) to visualize the progress of interactive build-up of a solution of a business case by the student's team. The visualization should show present consensus and stimulate further team discussion, everything in the context of cultural sensitivity embedded into the teaching process. The idea and creation of the mentioned cultural context were described in the paper (Kelsey \& Zaliwski, 2017b).

Considering the above goals, the research question can be expressed as follows:

What is the best method for smooth and interactive representation (metaphors and interfaces) of current state-of-knowledge about the business case under consideration, which also not distract the students involved in the discussion?

Rationale:

1) In the currently existing tools like MS Project or Prezi, the interactive representation of ad-hoc ideas created during the discussion requires switching the software from presentation to edit mode, which usually breaks the discussion.

2) Utilizing 3D presentation allows to put additional "informational" dimension into the picture and brings interactivity to a new level. However, this depends on finding appropriate presentation metaphors for representing business facts and dependencies. This should also take into account multicultural considerations.

3) The accepted solutions should allow further research in the following directions:

a) Using students BYOD (Bring Your Own Device) like phones and tablets to enable remote editing the main picture on the large screen.

b) Using gamification for deeper immersion of students into the case story.

c) Using AI for analytics of a teaching process. 
Interactive 3D Representation of Business Case Studies

The following section contains the literature review, which allows exact understanding of what our tool is and what it is not by the comparison of our tool with the knowledge visualization tools and business intelligence tools. Anyway, our tool development is not going toward being another business intelligence tool.

\section{LITERATURE REVIEW}

In the literature can be found two common approaches showing some similarities to our approach. First one is called "business intelligence." The second approach is called "knowledge visualization." Between these two groups of solutions exists a whole spectrum of various business visualisation tools, e.g., used for big data visualisation (Braseth \& Øritsland, 2013; Eppler \& Platts, 2009; Gulden, 2015; Rubart, Lietzau, Söhlke, Alex, Becker, \& Wienböker, 2017; Wright, 2017), analytics (Sharma, Mithas, \& Kankanhalli, 2014; Slivkins \& Vaughan, 2014), and applications in Enterprise Information Systems (Gulden, 2015). Information-rich virtual environments are used for a variety of purposes for a long time (Bowman et. al., 2003). There also exist different approaches to network visualization, e.g., Henry, Fekete, and McGuffin (2007), Batagelj and Mrvar (2004), or Brandes and Wagner (2004). However, no one of it fits our purposes.

There is no doubt that business visualization adds value (Abulrub, Yin, \& Williams, 2012; Latour, 1986; Ware, 2012; Wright, 2017). For example, Wright (2017) gives a business example where visualization improves communication. Wright's paper is concluded by a practical note: if you want to make business users feel good with information visualization, the learning process must be a part of the application. That means, according to Wright, a new user should start from simple examples and next move to more complicated using advanced capabilities of the application.

As it was mentioned as the beginning of the literature review, we focus in this review only on the business intelligence systems (BIS) and visual knowledge transfer.

The business intelligence systems (BIS) (Bai, White, \& Sundaram, 2013) seems to be developed naturally from the popular at the end of previous century Group Decision Support Systems (GDSS). Business Intelligence Systems use for visualization is a kind of a dashboard, usually in a form of a combination of various visual components like views or charts. Business Intelligence Systems also may utilize OLAP (On-Line Analytical Processing) and Big Data analytics with a combination of video conferencing tools.

The BIS allows a meeting of several experts and executives (some may be present on-line) solving together a complicated business problem and having access to all company data. The BIS is used to deliver status of an organization and support managerial decisions. This, in fact, may be recognized as a sophisticated decision support system.

If we talk about BIS, the involved experts and managers already know methodologies and they have meaningful experience in solving problems. Whereas, our students need to identify where is a problem and understand the problem-solving process to be able to use it in the life situations as further experts and managers. So, if the two systems (BIS and ours) may be compared against each other, this may be only like the comparison between the real airplane and safe flight simulator.

The similarity of BIS to our proposed solution is that business case studies are created on a basis of real problems taken from some real companies. The solution discussed in this paper is rather designed to be used not as full business intelligence tool but rather "business flight simulator" focused on delivery to students' real business smell and taste of real-life situations. Additionally, the whole solution has in mind to be culturally inclusive (Irving \& Hoffman, 2014; Kutay, Howard-Wagner, Riley, \& Mooney, 2012; Wyeld \& Pumpa, 2007) and to create a safe space for multicultural students with special focus on Pacific area cultures. The solutions in specific are referring to the culturally embedded storytelling of Pacific nations and specific for them solving problems methodologies (Kosara \& Mackinlay, 2013; Leavy, Wyeld, Hills, Barker, \& Gard, 2007; Meyers, 2003; Vaioleti, 2016;). As already mentioned, earlier the communication medium is based on rich picture coming from Soft Sys- 
tem Methodology (SSM) (Checkland \& Poulter, 2010; Wigal, 2009). In our case presentation, the problem becomes more vibrant, attractive, and more detailed over time, bringing us closer to a solution. The different stories which build up a case study become straightened and unwired. The picture on the screen is not only a convenient way of displaying company's data, but it is a living mirror and a focal point of in-class discussion dynamically changed to reflect new ideas coming in and out. Each update during the discussion brings class to the next level of the problem and allows understanding the whole process of finding a solution (in fact the editor's picture can be considered as a kind of knowledge base). The editor does not employee complex analytical methods. Finally, we have a safe room for mistakes and experiments. This shapes requirements for the supporting tool.

The second big group of approaches to business visualization is "visual knowledge transfer". For example, Bertschi et. al. (2011) is talking about knowledge visualization as an emergent discipline. However, the biggest interest in visual knowledge transfer already took place since the year 2004 (Burkhard, 2004, 2005; Cañas et. al., 2006; Meyer, 2010; Schnotz, \& Kürschner, 2008).

To generalize we may say that using any diagram as a tool to communicate concepts in any team of people is a kind of visual knowledge transfer, that means a means of knowledge transfer among team members. In this context, we can find examples of picture-based knowledge transfer (in other words visual knowledge transfer as above) along with storytelling (Koki, 1998; Kosara \& Mackinlay, 2013) among all indigenous cultures (El-Hakim, Fryer, \& Picard, 2004; Fryer, Chandler, \& El-Hakim, 2005) everywhere over the world, e.g. Africa (Rodil, Winschiers-Theophilus, Bidwell, Eskildsen, Rehm, \& Kapuire, 2011) or aboriginal cultures in Australia (Irving \& Hoffman, 2014; Leavy, Wyeld, Hills, Barker, \& Gard, 2007).

Both business intelligence and visual knowledge transfer utilize various constructs like hierarchies, networks, various types of graphs, or tables to present relationships among different objects under consideration (e.g., people, documents, concepts, events.). Their visualization is implemented, for example, by concept maps (J. D. Novak \& Cañas, 2006), topic maps (Dicheva \& Dichev, 2006), and many others. In our case, there is used just simple so-called "rich pictures." The concept of the rich picture was described as a part of Soft Systems Methodology (SSM) and successfully used in various business and IT contexts more than 40 years (e.g., CATWOE since 1975). The SSM was created to solve business problems with the support of Information Technology as each IT methodology did before and after SSM was created. Since its beginning, it is used successfully on the borderland of Information Technology and Business to improve processes or services and in the longer term to enable sustained competitive advantage for the business under consideration. SSM is a tool for company's doctor (usually described as a system analyst) to understand and diagnose the problem. Next, it is prescribed organizational change and process redesign supported using information technology which enables doing a new process in an old way or old processes in a new way making the processes more efficient.

The above paragraph, in fact, describes nothing more than the process of system analysis and design. Later, the SSM (mostly as a diagnosis tool for system thinking) has been utilized for many other purposes. For example (Hindle, 2011) arguing that SSM is usable as a method to solve many kinds of problems in the context of experiential learning. He proposes SSM as a separate course module usable for better understanding or solving problems presented by the other courses whatever is that course topic. According to Hindle (2011), "[SSN] is an all-purpose approach to deal with complex problem situations, an approach that adopts experiential learning and uses system modeling to structure discussion between a group of participants". Critics of SSM (Jackson, 2000, p. 269) underline the fact that, if hard system thinking has limited application, SSM also cannot be properly employed. The advanced discussion of different aspects of system thinking can be found in Jackson (2007). The "cross-community learning" in (J. Novak, 2007; J. Novak \&Wurst, 2005). 


\section{DEVElopMENT DiRECTION - MAKE BUSINESS THINKING VISUAL}

In fact, teaching may be recognized as a knowledge transfer from the teacher toward the learners. In ancient time a supporting medium for knowledge transfer in the community was storytelling and pictures. Currently, we return to storytelling and pictures.

The core of the project described in this paper is to visualize the progress of interactive build-up of a solution of a business case by the student's team. The visualization is realized by the specialized, designed only for that purpose graphical editor. The visualization made by the editor should reflect the current discussion state and stimulate further discussion, everything in the context of cultural sensitivity embedded into the teaching process. In other words, around the editor will be built all of the social and cultural constructs presented in our previous paper (Kelsey \& Zaliwski, 2017b). To be able to perform the core role the graphical editor supporting the above processes must follow the following requirements:

- No switching between editor mode and presentation mode. For example, Prezi has an editing mode where a presentation is prepared and a separate mode when we present a ready-made presentation. However, in our case, the presentation is highly dynamic and must be changed on the fly. Each time when we want to make picture changes we need to switch to the edit mode which distracts students by showing unnecessary technical details related to the tool (like for example editing the picture and displaying menus and tools and handlers used to that edition). Whereas they are not related to the logical stream of solving the case problem. For the new tool, the difference between editing and presentation mode should be not visible (one-mode tool).

- Navigation over the network of facts, events, and relationships on a basis of connectivism learning theory. Shortly, connectivism assumes that knowledge resides in the sociotechnical networks. According to Siemens (2014), the basic concepts characterizing connectivism approach are (among the others):

1) Learning is a process of connecting nodes.

2) Learning and knowledge rest in diversity of opinions.

3) Learning may reside in non-human appliances.

The concepts on which the editor is built are more related to connectivism learning theory than constructivism (Hyslop-Margison, \& Strobel, 2007). For example, the editor link "local" picture of business taken from the case study (Figure 1) with external information sources implements the "connectivism style" interface. The case may be interpreted as a network of intertwined stories. The case text contains basic information about the problem context and symptoms but developed solutions may have consequences in a network of events which goes far behind the case study initial scope (Figure 1).

The metaphors are used for visual grouping of discussed and represented concepts in relationships to organization parts and people presented in the business case study under consideration. So far this is the only one legitimate reason to make the diagrams 3D, but not 2D.

- Zooming interface. The interface is where it is possible to see a birds-eye-view of a whole situation and also the detailed zooming view for a given aspect of a situation (Some examples are eagle-mode and Prezi which allows scaling of the presentation to show more details). The scaling from birds-eye-view to detailed view also should be seamless and not bother the audience by showing unnecessary technical details of the editor (e.g., menus or edit controls). 
- Interface with extension modules (the examples are listed in "Further Research" section).

- Versioning - returning to previous solutions (images) if current way becomes unsuccessful.

A business case does not contain all information necessary to find the most effective solution. The business case mimics the real business situation where the problem (opposite to mathematical) is wicked - we have incomplete information (marked as a case scope in Figure 1) and more than one solution is possible. We also do not have confidence that the accepted solution is optimal. In fact, we search for any satisfactory solution.

Additionally, the scope of the case and the problem may be seen differently by the different students accordingly to their culture, traditions, and beliefs in their home country. The software should also enable (when used) the creation of a safe space in the classroom, where students may feel comfortable using metaphors and concepts relating to their own culture. The language of graphics as universal may create a common understanding among multicultural students. Usable here is another Pacific Islander concept of "learning village" (Chu, Abella, \& Paurini, 2013; Nanai et. al. 2011; Vaioletti, 2006, 2011) understood as a safe, culturally strengthening place where friendly community concepts (Vescio, Ross, \& Adams, 2008) may be implemented for the students in the classroom. The concept is also present in African Ubuntu (Lutz, 2009): "It takes a village to raise a child (Nafukho, 2006, p. 412)".

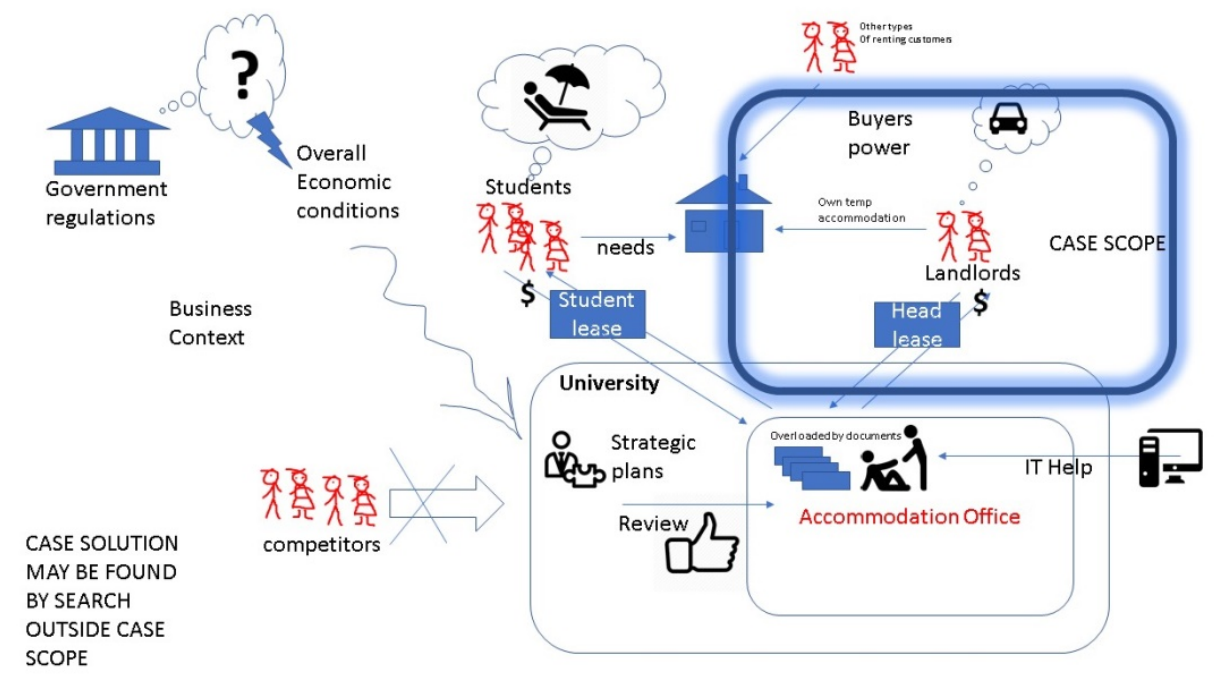

Figure 1. The information required to solve case study usually exceeds this contained in case paper. The background picture of "Accommodation Office" case is based on (Nguyen, 2018).

The visualization and visualization metaphors are inherited from "rich picture" as we were fascinated by the people who drew a lecture in the form of the story while presenting. Not everybody is a cartoonist or artist to make it. The ad-hoc drawing picture as a method of in-class presentation is very attractive and brings students' attention. Rich picture, due to lack of formal rules, also enables imaging of culturally embedded concepts.

However, we consider eventual modification related to the background, adding additional contextrelated information (Figure 2 contains an example of this type background information) by projecting the above relationship into organizational context (this will apply only for suitable case studies). The contextual background was created by showing the sources of company's sustained competitive advantage. The boxes on the right side show which learning topics can be applied at a given point. The information from the editor may be visualized over this 3D context to add additional information to the display. 


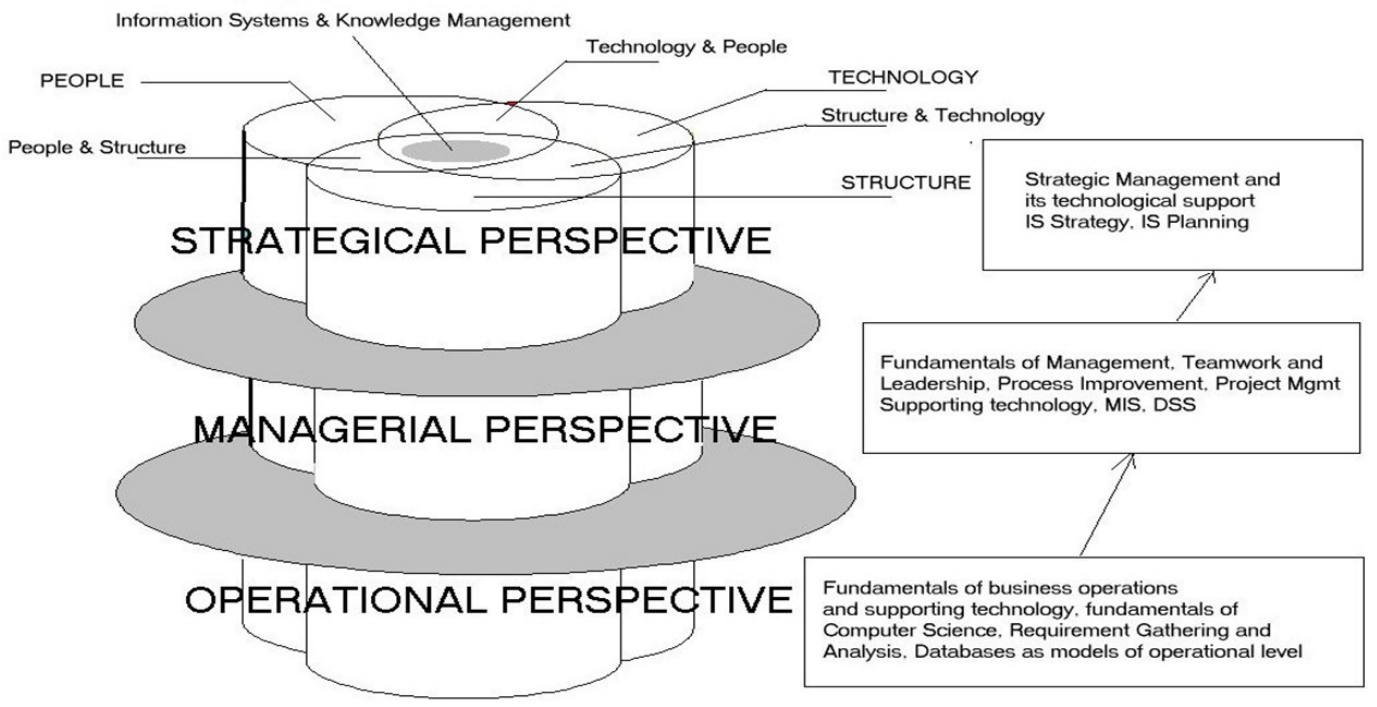

Figure 2. Sample contextual background to use for rich picture placement [Source. Removed].

\section{FURTHER RESEARCH}

Planned development directions:

- Providing the extension of the teaching tools toward the improvement of learning effects for teaching company's executives and high-level staff. The current results obtained in researching students since 2010 are promising (especially in the multicultural environment).

- Obtaining teaching process analytics in long-term perspective to collect insights on future improvements (by adding an AI layer).

- Identity (and eventually create new) business models in effect of learning from the student's discussions (by adding the AI layer).

- Extend the user interface base. The possibility of using a wide variety of graphical interfaces is potentially unlimited (e.g., mobile phones or VR in the future).

- Branching of the solution into gamification (e.g. define and generate the game by "rich picture" scenario) and automated solutions (e.g. "rich picture" items will be retrieved from the library of pre-defined shapes using case study text analysis. That way we will have the correct set of symbols ready to use before we start the class. The rich picture when subjected to gamification demands an artistic approach, thereby creating the ideal collaborative environment for the fusion of artists, art, technology, and education (Kelsey \& Zaliwski, 2017a).

- There is also lack of appropriate business case studies which are fit completely to the proposed method. This problem will be addressed later.

\section{CONCLUSION}

The method of teaching case studies described in this and in the series of previous papers (Kelsey \& Zaliwski, 2014; 2017a; 2017b; Zaliwski \& Kelsey, 2015a, 2015b, 2016, 2017) is used successfully since the year 2010. However, preparation of materials and class sessions requires an enormous amount of time. The current research is going toward reducing preparation time and providing computerized tools for both a core visualization of in-class activities and for prior preparation of in-class materials. 
The proposed visualization/editing tool will enable ways for further development and will be the primary tool for the visual knowledge transfer.

The editor, however, is still under development using Python with Blender (Conlan, 2017; Kent, 2015) an open source application used by the artists and game developers. During the Conference, the presentation will be provided a presentation of the prototype.

\section{REFERENCES}

Abulrub, A.-H., Yin, Y., \& Williams, M. (2012). Acceptance and management of innovation in SMEs: Immersive 3D visualisation. Procedia - Social and Behavioral Sciences, 41, 304-314. https://doi.org/10.1016/j.sbspro.2012.04.035

Ambrosini, V., Bowman, C., \& Collier, N. (2010). Using teaching case studies for management research. Strategic Organization, 8(3), 206-229. https://doi.org/10.1177/1476127010374254

Arasti, Z., Falavarjani, M. K., \& Imanipour, N. (2012). A study of teaching methods in entrepreneurship education for graduate students. Higher Education Studies, 2(1), 2-10. https://doi.org/10.5539/hes.v2n1p2

Bai, X., White, D., \& Sundaram, D. (2013). Context adaptive visualization for effective business intelligence. 2013 15th IEEE International Conference on Communication Technology, 786-790. https://doi.org/10.1109/ICCT.2013.6820481

Batagelj, V., \& Mrvar, A. (2004). Pajek-analysis and visualization of large networks. In M. Jünger \& P. Mutzel (Eds.), Graph drawing software (pp. 77-103). Berlin, Heidelberg: Springer. https://doi.org/10.1007/978-3$\underline{642-18638-7 \quad 4}$

Bertschi, S., Bresciani, S., Crawford, T., Goebel, R., Kienreich, W., Lindner, M., ... \& Moere, A. V. (2011). What is knowledge visualization? Perspectives on an emerging discipline. In Information Visualisation (IV), 2011 15th International Conference on (pp. 329-336). IEEE. https://doi.org/10.1109/IV.2011.58

Bowman, D. A., North, C., Chen, J., Polys, N. F., Pyla, P. S., \& Yilmaz, U. (2003, October). Information-rich virtual environments: Theory, tools, and research agenda. In Proceedings of the ACM symposium on Virtual Reality Software and Technology (pp. 81-90). ACM. https://doi.org/10.1145/1008653.1008669

Brandes, U., \& Wagner, D. (2004). Analysis and visualization of social networks. In M. Jünger \& P. Mutzel (Eds.), Graph drawing software (pp. 321-340). Berlin, Heidelberg: Springer. https://doi.org/10.1007/978-3$\underline{642-18638-7 \quad 15}$

Braseth, A. O., \& Øritsland, T. A. (2013). Seeing the big picture: Principles for dynamic process data visualization on large screen displays. In Proceedings of the International Conference on Complexity, Cybernetics and Informing Science and Engineering (pp. 16-22). http://www.academia.edu/download/31990950/CCISE2013.pdf\#page $=28$

Burkhard, R. A. (2004, July). Learning from architects: The difference between knowledge visualization and information visualization. In Information Visualisation, 2004. IV 2004. Proceedings. Eighth International Conference on (pp. 519-524). IEEE. https://www.alexandria.unisg.ch/21020/1/2004 Burkhard Learning $\% 20$ from $\% 20$ Architects.pdf

Burkhard, R. A. (2005). Towards a framework and a model for knowledge visualization: Synergies between information and knowledge visualization. In S.-O. Tergan \& T. Keller (Eds.), Knowledge and information visualization (pp. 238-255). Berlin, Heidelberg: Springer. https://doi.org/10.1007/11510154 13

Cañas, A. J., Carff, R., Hill, G., Carvalho, M., Arguedas, M., Eskridge, T. C., ... \& Carvajal, R. (2005). Concept maps: Integrating knowledge and information visualization. In S.-O. Tergan \& T. Keller (Eds.), Knowledge and information visualization (pp. 205-219). Berlin, Heidelberg: Springer.

Checkland, P., \& Scholes, J., (1990). Soft systems methodology in action. Chichester Wiley.

Checkland, P. (2000). Soft systems methodology: A thirty year retrospective. Systems Research and Behavioral Science, 17(S1), S11. https://doi.org/10.1002/1099-1743(200011)17:1+<::AID-SRES374>3.0.CO;2-O 
Interactive 3D Representation of Business Case Studies

Checkland, P., \& Winter, M. (2006). Process and content: Two ways of using SSM. Journal of the Operational Research Society, 57(12), 1435-1441. https://doi.org/10.1057/palgrave.jors.2602118

Checkland, P., \& Poulter, J. (2010). Soft systems methodology. In M. Reynolds \& S. Holwell (Eds.), Systems approaches to managing change: A practical guide (pp. 191-242). London: Springer. https://doi.org/10.1007/978-1$\underline{84882-809-4 \quad 5}$

Chu, C, Abella, I. S., \& Paurini, S. (2013). Educational practices that benefit Pacific learners in tertiary education. Wellington. Ako Aotearoa. National Centre for Tertiary Teaching Excellence. Retrieved from https://www.akoaotearoa.ac.nz/mi/download/ng/file/group-5330/fr-educational-practices-thatbenefitpacific-learners-in-tertiary-education.pdf

Conlan, C., (2017). The Blender Python API: Precision 3D modeling and add-on development. Apress 2017. https://doi.org/10.1007/978-1-4842-2802-9

Cundill, G., Cumming, G. S., Biggs, D., \& Fabricius, C. (2012). Soft systems thinking and social learning for adaptive management. Conservation Biology, 26(1), 13-20. https://doi.org/10.1111/j.1523-1739.2011.01755.x

Dicheva, D., \& Dichev, C. (2006). TM4L: Creating and browsing educational topic maps. British Journal of Educational Technology, 37(3), 391-404. https://doi.org/10.1111/j.1467-8535.2006.00612.x

Duarte, F. P. (2013). Conceptions of good teaching by good teachers: Case studies from an Australian university. Journal of University Teaching and Learning Practice, 10(1), 5.

Eppler, M. J., \& Burkhard, R. A. (2004). Knowledge Visualization. Università della Svizzera Italiana. http://doc.rero.ch/record/5196/files/1 wpca0402.pdf

Eppler, M. J., \& Burkhard, R. A. (2006). Knowledge visualization. In D. Schwartz (Ed.), Encyclopedia of knowledge management (pp. 551-560). IGI Global. https://doi.org/10.4018/978-1-59140-573-3.ch072

Eppler, M. J., \& Platts, K. W. (2009). Visual strategizing: The systematic use of visualization in the strategicplanning process. Long Range Planning, 42(1), 42-74. https://doi.org/10.1016/j.lrp.2008.11.005

El-Hakim, S. F., Fryer, J. G., \& Picard, M. (2004). Modeling and visualization of aboriginal rock art in the Baiame cave. International Archives of Photogrammetry and Remote Sensing, 35(5), 990-995.

Fryer, J., Chandler, J., \& El-Hakim, S. (2005, November). Spatial modelling an aboriginal cave painting: Easy with modern technology. In Annual Colloquium of the Spatial Information Research Centre University of Otago, Dunedin, New Zealand.

Gulden, J. (2015). A description framework for data visualizations in enterprise information systems. 2015 IEEE 19th International Enterprise Distributed Object Computing Conference, 68-73. https://doi.org/10.1109/EDOC.2015.20

Harner, M. M., \& Rhee, R. J. (2014). Deal deconstructions, case studies, and case simulations: Toward practice readiness with new pedagogies in teaching business and transactional law. Retrieved from https://scholarship.law.ufl.edu/cgi/viewcontent.cgi?article=1486\&context=facultypub

Henry, N., Fekete, J. D., \& McGuffin, M. J. (2007). NodeTrix: A hybrid visualization of social networks. IEEE Transactions on Visualization and Computer Graphics, 13(6), 1302-1309. https://doi.org/10.1109/TVCG.2007.70582

Herreid, C. F. (2004). Can case studies be used to teach critical thinking? Journal of College Science Teaching, 33(6), 12-14.

Herreid, C. F. (2006). "Clicker" cases: Introducing case study teaching into large classrooms. Journal of College Science Teaching, 36(2), 43.

Hindle, G. A. (2011). Case article_-Teaching soft systems methodology and a blueprint for a module. INFORMS Transactions on Education, 12(1), 31-40. https://doi.org/10.1287/ited.1110.0068ca

Hyslop-Margison, E. J., \& Strobel, J. (2007). Constructivism and education: Misunderstandings and pedagogical implications. The Teacher Educator, 43(1), 72-86. https://doi.org/10.1080/08878730701728945

Irving, L., \& Hoffman, J. (2014). Nyungar Place stories pilot: Using augmented reality for indigenous cultural sustainability. Rhetoric and Reality, 367-378. Retrieved from 
https://www.researchgate.net/profile/Leah Irving/publication/301692539 Nyungar Place Stories Pilot using augmented reality for Indigenous cultural sustainability/links/5722bfba08ae586b21d3fd12.pdf

Jackson, M. C., (2000). Systems approaches to management. Kluwer Academic/Plenum, New York. Note: Newest edition:

Jackson, M. C., (2007). Systems approaches to management. Springer Science \& Business Media. (also, Google Books).

Kelsey, K., \& Zaliwski, A. (2014). Applied business education: The Cultural Impact on Interactive Teaching in a MultiCultural Learning Environment. Weltec-Whitireia Auckland Research Symposium. Wellington $20^{\text {th }}$ Nov. 2014.

Kelsey, K., Zaliwski, A. (2017a). Bringing the art to applied business education. The 7th World Alliance for Arts Education Conference. Engaging with Communities. Creative Pedagogies. Auckland University. Auckland, New Zealand, 22-25 November 2017.

Kelsey, K., \& Zaliwski, A. J., (2017b). Let's tell the story together (Visualisation of Case Studies). Interdisciplinary Journal of e-Skills and Lifelong Learning, 13, 97-115. https://doi.org/10.28945/3763

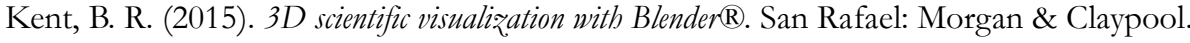
https://doi.org/10.1088/978-1-6270-5612-0

Koki, S. (1998). Storytelling: The heart and soul of education. PREL Briefing Paper. Pacific Resources for Education and Learning, Honolulu, HI. Office of Educational Research and Improvement (ED), Washington, DC.

Kosara, R., \& Mackinlay, J. (2013). Storytelling: The next step for visualization. Computer, 46(5), 44-50. https://doi.org/10.1109/MC.2013.36

Kutay, C., Howard-Wagner, D., Riley, L., \& Mooney, J. (2012). Teaching culture as social constructivism. In Advances in Web-Based Learning-ICWL 2012 (pp. 61-68). Springer Berlin Heidelberg. https://doi.org/10.1007/978-3-642-33642-3 7

Latour, B. (1986). Visualization and cognition. Knowledge and Society, 6(6), 1-40. http://hci.ucsd.edu/10/readings/Latour(1986).pdf

Leavy, B., Wyeld, T. G., Hills, J., Barker, C., \& Gard, S. (2007). Digitizing the arts, culture and heritage landscape of Aboriginal Australia. In Y. Kalay, T. Kvan, \& J. Affleck (Eds.). New heritage: New media and cultural heritage, 294-303.

Ledington, P., \& Donaldson, J., (1997). Soft OR and management practice: A study of the adoption and use of soft systems methodology. Journal of the Operational Research Society. 48(3), 229-240. https://doi.org/10.1057/palgrave.jors. 2600350

Lutz, D. W. (2009). African Ubuntu philosophy and global management. Journal of Business Ethics, 84(3), 313. https://doi.org/10.1007/s10551-009-0204-z

Meyer, R. (2010). Knowledge visualization. Trends in Information Visualization, 23. http://www.mmi.ifi.lmu.de/pubdb/publications/pub/baur2010infovisHS/baur2010infovisHS.pdf\#page $=31$

Meyers, M. A. (2003). Ho'oulu: Our time of becoming-Hawaiian epistemology and early writings (1st ed.). Hawaii: Hawaii Native Books Inc.

Munro, I., \& Mingers, J., (2002). The use of multimethodology in practice-Results of a survey of practitioners. Journal of the Operational Research Society, 53(4), 369-378. https://doi.org/10.1057/palgrave.jors.2601331

Nafukho, F. M. (2006). Ubuntu worldview: A traditional African view of adult learning in the workplace. $A d-$ vances in Developing Human Resources, 8(3), 408-415. https://doi.org/10.1177/1523422306288434

Nanai, J. B., Smith, N., Hogg, R., Rasheed, A., Ahio, L., \& Samuela, J. S. (2011). A Pasifika learning village: The way forward.

Nguyen, T., (2018). Rich picture example. Slideshare. https://www.slideshare.net/tatdy13/mcki-lect3ssmcatrdroseusund (whereas the original case example comes from Edwards \& Humphries. Rich Pictures. (University of Sunderland) http://osiris.sunderland.ac.uk/ cs0hed/csem04/ CSEM04Unit10richpictures.ppt 24/9/10 (no longer accessible). 
Interactive 3D Representation of Business Case Studies

Novak, J. (2007, January). Helping knowledge cross boundaries: Using knowledge visualization to support cross-community sensemaking. In System Sciences, 2007. HICSS 2007. 40th Annual Hawaii International Conference on (pp. 38-38). IEEE. http://citeseerx.ist.psu.edu/viewdoc/download?doi=10.1.1.93.9200\&rep=rep1\&type=pdf

Novak, J., \& Wurst, M. (2005). Collaborative knowledge visualization for cross-community learning. In Knowledge and Information Visualization (pp. 95-116). Berlin, Heidelberg: Springer. https://doi.org/10.1007/11510154_6

Novak, J. D., \& Cañas, A. J. (2006). The origins of the concept mapping tool and the continuing evolution of the tool. Information Visualization, 5(3), 175-184. https://doi.org/10.1057/palgrave.ivs.9500126

Rodil, K., Winschiers-Theophilus, H., Bidwell, N. J., Eskildsen, S., Rehm, M., \& Kapuire, G. K. (2011, September). A new visualization approach to re-contextualize indigenous knowledge in rural Africa. In IFIP Conference on Human-Computer Interaction (pp. 297-314). Berlin, Heidelberg: Springer. https://link.springer.com/content/pdf/10.1007/978-3-642-23771-3 23.pdf

Rubart, J., Lietzau, B., Söhlke, P., Alex, B., Becker, S., \& Wienböker, T. (2017). Semantic navigation and discussion in a digital boardroom. 2017 IEEE 11th International Conference on Semantic Computing (ICSC) (pp. 290296). https://doi.org/10.1109/ICSC.2017.39

Schnotz, W., \& Kürschner, C. (2008). External and internal representations in the acquisition and use of knowledge: Visualization effects on mental model construction. Instructional Science, 36(3), 175-190. https://doi.org/10.1007/s11251-007-9029-2

Sharma, R., Mithas, S., \& Kankanhalli, A. (2014). Transforming decision-making processes: A research agenda for understanding the impact of business analytics on organisations. European Journal of Information Systems, 23(4), 433-441. https://doi.org/10.1057/ejis.2014.17

Shugan, S. M. (2006). Save research-Abandon the case method of teaching. Marketing Science, 25(2), 109-115. https://doi.org/10.1287/mksc.1060.0202

Siemens, G. (2014). Connectivism: A learning theory for the digital age. Retrieved from http://er.dut.ac.za/bitstream/handle/123456789/69/Siemens 2005 Connectivism A learning theory $f$ or the digital age.pdf

Slivkins, A., \& Vaughan, J. W. (2014). Online decision making in crowdsourcing markets: Theoretical challenges. ACM SIGecom Exchanges, 12(2), 4-23. https://doi.org/10.1145/2692359.2692364

Vescio, V., Ross, D., \& Adams, A. (2008). A review of research on the impact of professional learning communities on teaching practice and student learning. Teaching and Teacher Education, 24(1), 80-91. https://doi.org/10.1016/j.tate.2007.01.004

Vaioleti, T. M. (2006). Talanoa research methodology: A developing position on Pacific research. Waikato Journal of Education, 12(1), 21-34. Retrieved from http://www.wje.org.nz/index.php/WJE/article/view/296/310

Vaioleti, T. M. (2011). Talanoa, Manulua and Founga Ako: Frameworks for using enduring Tongan educational ideas for Education in Aotearoa/New Zealand. Ph.D. Thesis University of Waikato. Retrieved from http://researchcommons.waikato.ac.nz/bitstream/handle $/ 10289 / 5179 /$ thesis.pdf?sequence $=3 \&$ is Allowed 三y

Vaioleti, T. M. (2016). Talanoa research methodology: A developing position on Pacific research. Waikato Journal of Education, 12(1). https://doi.org/10.15663/wje.v12i1.296

Wigal, C. (2009). Special session - Using rich pictures to improve systemic thinking. 2009 39th IEEE Frontiers in Education Conference, 1, 1-2. https://doi.org/10.1109/FIE.2009.5350606

Winter, M. (2006). Problem structuring in project management: An application of soft systems methodology (SSM). Journal of the Operational Research Society, 57(7) 802-812. https://doi.org/10.1057/palgrave.jors. 2602050

Ware, C. (2012). Information visualization: perception for design. Elsevier. http://ifs.tuwien.ac.at/ silvia/wien/vuinfovis/articles/book information-visualization-perception-for-design Ware Chapter1.pdf 
Wright, W. (2017). Business visualization adds value. IEEE Computer Graphics and Applications, 18(4), 39. https://doi.org/10.1109/38.689660

Wyeld, T. G., \& Pumpa, M. (2007, July). Narratological constructs in the Gestalt of the 3D game environment: Aboriginal knowledge and its connection to the data landscape metaphor. In Information Visualization, 2007.

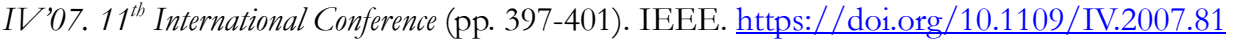

Zaliwski, A.J., (2003). "Step Toward Information Systems Curriculum Based on Knowledge Management Framework," IIAS-Transaction on Systems Research and Cybernetics, Vol. III, No. 1 (2003). International Journal of the International Institute for Advanced Studies in Systems Research and Cybernetics. Canada. ISSN 1609-8625. pp. 17-21.

Zaliwski, A.J. (2010). Collaborative authoring of learning objects for blended learning. Poster at eResearch Australasia Conference, Gold Coast.

Zaliwski, A.J. (2013). Engaging audiences by the non-linear presentation and case studies. Presentation at the Whitireia Auckland Research Symposium. Oct. 2013.

Zaliwski, A., Kelsey, K. (2015a). Building interaction with multicultural students - A fusion of multiple ancient and modern teaching technologies. The European Conference on Education 2015, ECE 2015, Brighton, East Sussex, United Kingdom, 1-5 July 2015.

Zaliwski, A., Kelsey, K. (2015b). Building interaction with multicultural students - Creating in-depth understanding through visualisation of case studies. HERDS A New Zealand, Tertiary Education Research in New Zealand TERNZ Conference, Auckland University of Technology. Auckland, 25 - 27 November 2015.

Zaliwski, A., Kelsey, K. (2016). The concept of blended cooperative course authoring. HERDS A New Zealand, Tertiary Education Research in New Zealand TERNZ Conference, University of Otago, Dunedin, New Zealand. 28 Nov. - 2nd Dec. 2016.

Zaliwski, A., Kelsey, K. (2017). The blended co-operative course authoring. Presentation at STEM-TEC Seminar. Auckland University of Technology. Auckland, 2 May 2017.

\section{BIOGRAPHIES}

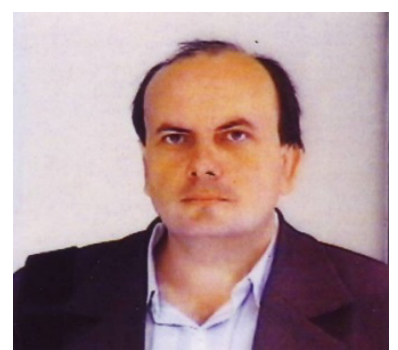

Andrew J. Zaliwski received an M.Sc. in Mathematics from the M.C. Sklodowska University (Poland) in 1986, and a Ph.D. in Computer Science from the University of Mining and Metallurgy (AGH), Krakow (Poland) in 1992. 1984-1990 he worked at UMCS Lublin (Poland), 1990-2000 as a lecturer at the Computer Science; the University of Economics, Krakow (Poland), and he worked 2000-2001 as the lecturer at the Computer Science Dept., University College Cork (Ireland). 2001 - 2006 he worked at the CUNY New York (CSI) as the business information systems lecturer. He is currently teaching "Project Management" and "Mobile Applications" at Whitireia NZ (Auckland, New Zealand). His current research interests include combining 3D graphics with computerized support for teaching and education and new STEM teaching solutions. 


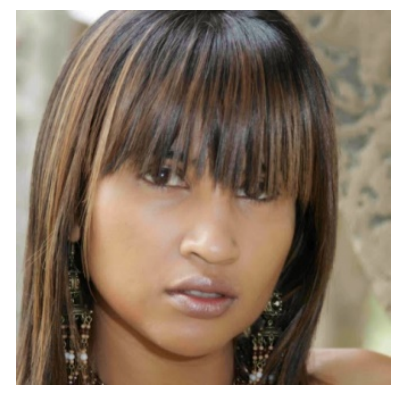

Karishma Kelsey has her Bachelors of Technology (Honors) in Design and Business from the Durban University of Technology in South Africa, a postgraduate in education from the University of South, and postgraduate work in the English language as a foreign and second language. She is also an active entrepreneur, who runs the fair-trade women empowerment Design Company, where the focus is on the ethical production and sustainable practice of clothing whilst building communities through skills development and several other sustainable practices. She has successfully created two workshops for women in Thailand and South Africa and is currently creating a workshop in Sri Lanka. She has been an educator of primary and secondary education in six different countries and has been challenged by many of the learning issues discussed in this paper. For the last 16 years, Kelsey has been researching and implementing creative methods of teaching and is passionate about the improvement of education for the empowerment of people. She is currently teaching e-Commerce and previously "Strategic Human Resource Management" at Whitireia NZ. Her current research interest includes analysis of supply chains in fashion industry companies, research commercialization, 3D graphics, and the adoption of game technologies into blended learning. 